OPEN ACCESS

Edited by:

Zhichao Fan,

UCONN Health, United States

Reviewed by: Yi Zhang,

Fudan University, China

Bo Liu,

Institut Pasteur of Shanghai (CAS),

China

${ }^{*}$ Correspondence:

Zhiguang Zhou

zhouzhiguang@csu.edu.cn

Specialty section: This article was submitted to Autoimmune and

Autoinflammatory Disorders,

a section of the journal

Frontiers in Immunology

Received: 28 July 2021 Accepted: 02 September 2021 Published: 17 September 2021

Citation:

Liu Y, Chen H, Chen Z, Qiu J, Pang H and Zhou Z (2021) Novel Roles of the Tim Family in Immune Regulation and Autoimmune Diseases. Front. Immunol. 12:748787. doi: 10.3389/fimmu.2021.748787

\section{Novel Roles of the Tim Family in Immune Regulation and Autoimmune Diseases}

\author{
Yikai Liu, Hongzhi Chen, Zhiying Chen, Junlin Qiu, Haipeng Pang and Zhiguang Zhou* \\ National Clinical Research Center for Metabolic Diseases, Key Laboratory of Diabetes Immunology, Ministry of Education, and \\ Department of Metabolism and Endocrinology, The Second Xiangya Hospital of Central South University, Changsha, China
}

T cell Ig and mucin domain (Tim) protein family members were identified to be important regulators of the immune response. As their name indicates, Tim proteins were originally considered a $T$ cell-specific markers, and they mainly regulate the responses of $T$ helper cells. However, accumulating evidence indicates that Tims are also expressed on antigenpresenting cells (APCs), such as monocytes, macrophages, dendritic cells (DCs) and B cells, and even plays various roles in natural killer cells (NKs) and mast cells. In recent years, the expression and function of Tims on different cells and the identification of new ligands for the Tim family have suggested that the Tim family plays a crucial role in immune regulation. In addition, the relationship between Tim family gene polymorphisms and susceptibility to several autoimmune diseases has expanded our knowledge of the role of Tim proteins in immune regulation. In this review, we discuss how the Tim family affects immunomodulatory function and the potential role of the Tim family in typical autoimmune diseases, including multiple sclerosis (MS), rheumatoid arthritis (RA), systemic lupus erythematosus (SLE) and type 1 diabetes (T1D). A deeper understanding of the immunoregulatory mechanism of the Tim family might provide new insights into the clinical diagnosis and treatment of autoimmune diseases.

Keywords: Tim, autoimmune diseases, multiple sclerosis, rheumatoid arthritis, systemic lupus erythematosus, type 1 diabetes

\section{INTRODUCTION}

Autoimmune diseases are characterized by abnormal tolerance to self-antigens that cause damage to body tissues (1). The etiology of autoimmune diseases is multifactorial and includes infection, environment and genetics (2-6). Most of these factors have been reported to be associated with immune disorders. Therefore, a better understanding of autoimmune disease pathogenesis is needed to identify better treatments. 
T cell Ig and mucin domain (Tim), a transmembrane glycoprotein, has been identified as one of the three human Tim family members (Tim-1, Tim-3, and Tim-4) that play a key role in regulating immunity in conditions such as allergies, asthma, virus infection and transplant tolerance (7-11). In the immune system, Tim-1 has been reported to be preferentially expressed on T helper type 2 (Th2) cells, where it serves as an effective costimulatory molecule for $\mathrm{T}$ cell activation (12). Tim-3 was first identified as being expressed on interferon- $\gamma($ IFN- $\gamma$ )producing Th1 cells. As an inhibitor of inflammatory Th1 cells, Tim-3 interacts with its ligand to cause the death of Th1 cells, thereby reducing IFN- $\gamma$ production (13). Tim-4 is a natural ligand of Tim-1. Tim-4 is mainly expressed on antigenpresenting cells (APCs), but not on T cells (14), and it participates in autoimmune diseases by regulating the proliferation of $\mathrm{T}$ cells (15). However, in recent studies, Tims were shown to be expressed on other immune cell types, such as macrophages, dendritic cells (DCs), natural killer cells (NKs) and B cells (16-19), and may play a critical role in maintaining immune homeostasis. These findings allow us to improve our knowledge of the role of Tims in the immune system. In this review, we focus on the expression and function of Tims on different immune cells, discuss recent studies examining the role of Tims in autoimmune diseases in both animal models and humans, and provide useful insights into the identification of new therapeutic targets.

\section{THE EXPRESSION AND FUNCTION OF TIMS ON DIFFERENT CELL TYPES}

Since the discovery of Tims in 2001, major progress has been achieved in terms of elucidating their characteristics and immunological functions (Table 1). In mice, the Tim family is composed of eight members (Tim-1 to Tim-8), and the genes that encode them are located on chromosome 11B1.1. In humans, three members (Tim-1, Tim-3, and Tim-4) have been identified, and the genes are located on chromosome 5q33.2 (Figure 1) (20). These three human Tim genes are most homologous to mouse Tim-1, Tim-3 and Tim-4, which are associated with allergic diseases. All Tim molecules are type I glycosylated proteins. Tim proteins contain an $\mathrm{IgV}$ domain, a mucin domain, a transmembrane domain, and an intracellular domain (Figure 2). Tim- 1 and Tim- 3 contain a tyrosine phosphorylation motif in the intracellular domain. Tim-3 has the shortest mucin domain and fewest predicted glycosylation sites. Tim- 4 differs from the other family members, and it contains a short intracellular tail without a tyrosine phosphorylation motif. In addition, Tim- 4 possesses an

TABLE 1 | Known features of the Tim family.

\begin{tabular}{|c|c|c|c|c|c|}
\hline Molecule & Expressing cells & Ligand(s) & Function & Disease & Ref \\
\hline Tim-1 & $\begin{array}{l}\text { Activated Th2 cells, } \\
\text { Bregs }\end{array}$ & $\begin{array}{l}\text { Tim-4 } \\
\text { PS }\end{array}$ & $\begin{array}{l}\text { Costimulation of T cell activation, } \\
\text { modulation of Treg function, } \\
\text { maintenance and induction of Bregs }\end{array}$ & $\begin{array}{l}\text { Autoimmune diseases, } \\
\text { infection, } \\
\text { asthma, } \\
\text { allergy }\end{array}$ & $(12,20)$ \\
\hline Tim-3 & $\begin{array}{l}\text { Th1 cells, } \\
\text { innate immune cells }\end{array}$ & $\begin{array}{l}\text { Gal-9 } \\
\text { HMGB1 } \\
\text { Ceacam1 } \\
\text { PS }\end{array}$ & $\begin{array}{l}\text { Suppression of the Th1 response, } \\
\text { increased activation of signaling pathways leading to } T \text { cell activation }\end{array}$ & $\begin{array}{l}\text { Autoimmune diseases, } \\
\text { infection, } \\
\text { cancer }\end{array}$ & $(13,21)$ \\
\hline Tim-4 & APCs & $\begin{array}{l}\text { Tim-1 } \\
\text { PS }\end{array}$ & $\begin{array}{l}\text { Regulation of T cell proliferation, } \\
\text { clearance of apoptotic cells }\end{array}$ & $\begin{array}{l}\text { Autoimmune diseases, } \\
\text { chronic metabolic disease, } \\
\text { infection, } \\
\text { allergy }\end{array}$ & $(15,22)$ \\
\hline
\end{tabular}
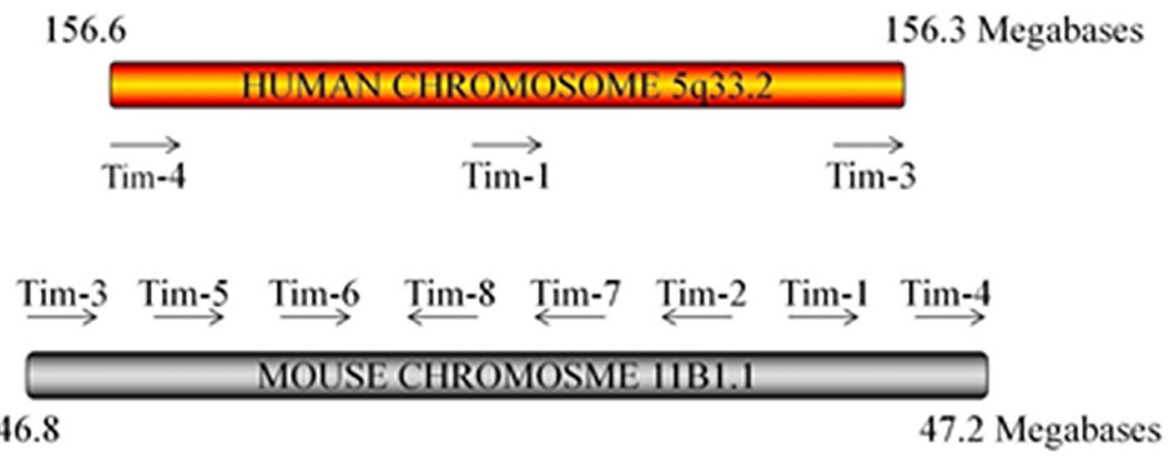

FIGURE 1 | Tim locus. The arrangement of the three Tim genes on human chromosome 5 and the 8 Tim genes on mouse chromosome 11 is shown. Mouse Tim-5-8 are predicted genes. The arrow indicates the direction of mRNA transcription. 


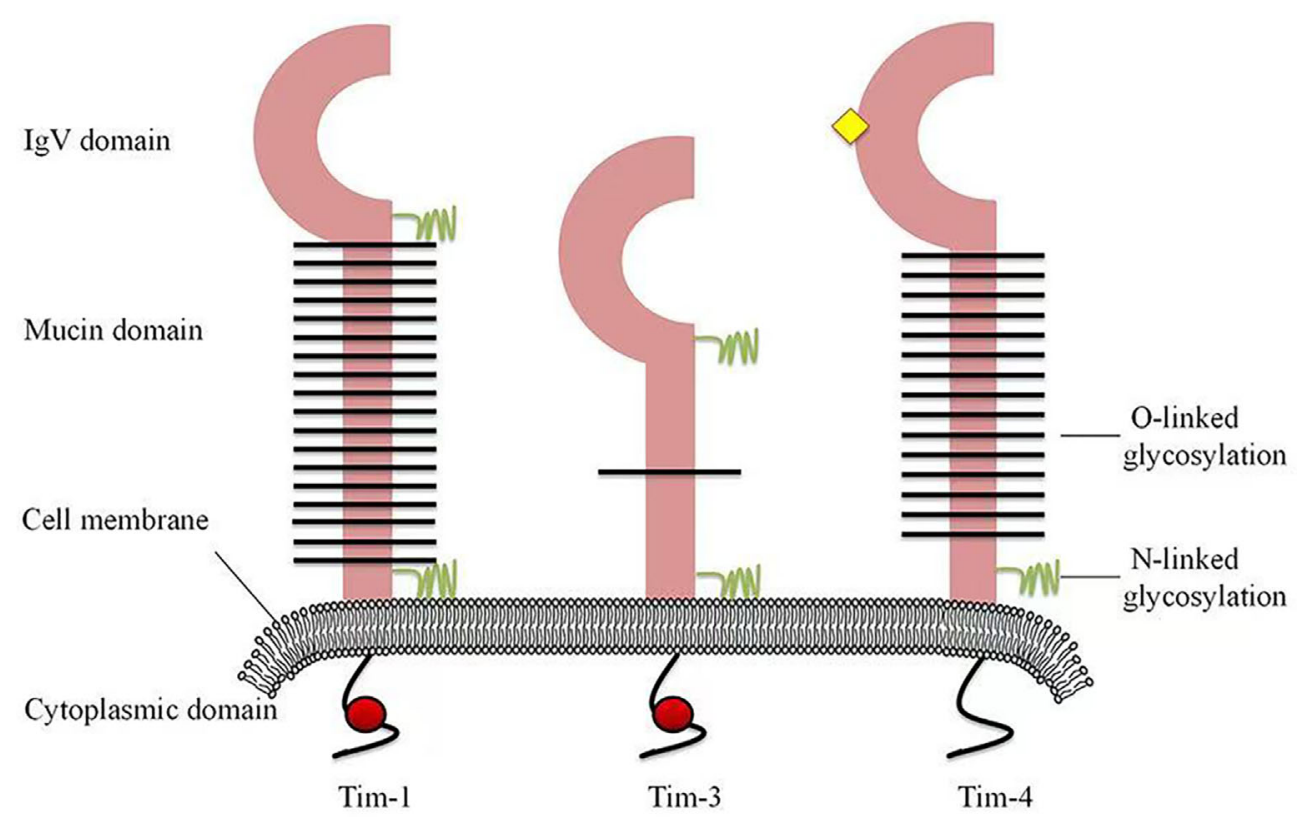

FIGURE 2 | Structures of human Tim family members. Tim proteins contain an IgV domain, a mucin domain, a transmembrane domain and an intracellular domain. Tim-3 has the shortest mucin domain and fewest predicted glycosylated site of the Tims. Tim-4 contains an arginine-glycine-aspartic acid (RGD) motif (yellow diamond), which is present in many ligands that bind to integrins. However, Tim-4 has no tyrosine phosphorylation site (red circle).

arginine-glycine-aspartic acid (RGD) motif, which is present in many ligands that bind to integrins (20). Therefore, Tim-4 may also act as a decoy receptor. Variations in the structures and motifs of Tim family members indicate that individual Tim proteins may have different roles in signal transduction.

\section{Tim-1}

The expression of Tim-1, also known as kidney injury molecule1 (Kim-1), is highly upregulated on the surface of injured kidney epithelial cells (23). Its expression is increased in urine samples from patients with chronic kidney disease (24). Tim-1 has been used as a biomarker to assess the degree of injury in individuals with acute tubular necrosis. In addition to its role in kidney injury, Tim-1 was also detected in African green monkey kidney cells (6) and later identified in humans as a cellular receptor for hepatitis A virus, called HAVCR-1 (25).

Interestingly, Tim- 1 is present on activated but not naive $\mathrm{CD} 4^{+}$ $\mathrm{T}$ cells. Moreover, it is preferentially expressed on activated Th2 cells, but not Th1 cells (12). Tim-1 is a highly effective costimulatory molecule that promotes the formation of $\mathrm{T}$ cell receptors (TCRs) through agonistic anti-Tim-1 antibodies, which increase the proliferation of $\mathrm{CD}^{+} \mathrm{T}$ cells (12). According to recent studies, Tim-1 has a dual function as a $\mathrm{T}$ cell costimulator; it positively or negatively costimulates the $\mathrm{T}$ cell response according to the way it engages with T cells during T cell activation (26). Researchers tested a series of monoclonal antibodies (mAbs) against Tim-1 and identified two antibodies targeting Tim-1 that display distinct effects. One agonistic mAb (3B3) increases the production of the proinflammatory cytokines IFN- $\gamma$ and IL-17, increasing the severity of experimental autoimmune encephalomyelitis (EAE). In contrast, the antagonistic mAb RMT1-10 inhibits IFN- $\gamma$ and IL-17 production, alleviates the development of autoimmunity (26).

In addition to exerting regulatory effects on Th cells, Tim-1 is also vital for the function and development of regulatory $\mathrm{T}$ cells (Tregs). The anti-Tim-1 mAb 3B3 reduces forkhead box protein P3 (Foxp3) expression, prevents effector $\mathrm{T}$ cells (Teffs) from differentiating into Tregs and regulates the suppressive ability of Tregs, thereby preventing transplantation tolerance in mice (11). Tim-1 signaling in B cells plays an important role in maintaining the stability of the immune system and inhibiting autoimmune diseases. Recently, researchers generated Tim-1-mutant [Tim-1 ( $\Delta$ mucin $)]$ mice. Notably, the ability of regulatory B cells (Bregs) to produce IL-10 was compromised in these mutant mice (27). B cells with defective Tim-1 or Tim-1 mutations show reduced IL10 production and increased production of proinflammatory cytokines (28). Based on these studies, Tim-1 expressed in B cells participates in suppressing immune rejection. Other studies have also found that the expression of Tim-3 and Tim-1 on the surface of mouse mast cells promotes the secretion of the inflammatory factors IL-13, IL-6 and IL-4 (29). Thus, Tim-1 plays wideranging roles in various cells to regulate the immune system.

\section{Tim-3}

Tim-3 was first reported to be expressed on IFN- $\boldsymbol{\gamma}$-producing Th1 cells (21). Binding of Tim-3 to its ligand terminates Th1 immune responses, and Tim-3 expression is regulated by the transcription factor T-bet (30). Human Tim-3 shares $63 \%$ amino acid homology with mouse Tim-3. Mouse Tim-3 consists of 281 
amino acid residues, while its human homolog consists of 302 amino acid residues (31). The membrane-bound form of Tim-3 includes an $\mathrm{N}$-terminal IgV domain, a mucin domain, a transmembrane domain and a short cytoplasmic tail.

To date, Tim-3 expression has been detected on both innate and adaptive immune cells, such as DCs (32), mast cells (29), macrophages (33), NK cells (34), and $\mathrm{CD} 4^{+} \mathrm{T}$ and $\mathrm{CD}^{+} \mathrm{T}$ cells (35). In addition, Tim-3 may be expressed on Th17 cells, although at lower levels than in Th1 cells (36). Subsequently, Tim-3 was also shown to be expressed on Tregs and participate in immune regulation (37). The differential expression of Tim-3 on both innate and adaptive immune cells suggests that Tim-3 exerts different effects on the functions of these cells. In a published study, an anti-Tim-3 Ab was used to block Tim-3 signaling in a mouse model of autoimmune heart disease. The decreased expression of Tim-3 and CD80 on mast cells and macrophages reduces the level of cytotoxic $\mathrm{T}$ lymphocyteassociated protein 4 (CTLA-4) on the surface of $\mathrm{CD}^{+}{ }^{+} \mathrm{T}$ cells, resulting in a decrease in the number of Treg cells and aggravated myocarditis (38). These studies indicate that the Tim-3 signaling pathway affects the adaptive immune system by influencing the innate immune system.

\section{Tim-4}

Tim-4 contains an extracellular IgV domain, a glycosylated mucin domain and an intracellular tail, and it is mainly expressed on APCs, including DCs, NKT cells, B1 cells and macrophages (22).

According to the current knowledge of Tim-4, the interaction between Tim- 4 and its ligand plays an important role in the initiation of Th2 polarization. In DCs exposed to cholera toxin (CT) or/and peanut extract (PE), Tim-4 expression is increased and participates in triggering specific Th2 polarization and intestinal allergies $(39,40)$. Tim- 4 is a natural ligand for Tim1 , and emerging evidence suggests that the binding of Tim-1 to Tim-4 is involved in regulating $\mathrm{T}$ cell proliferation (41). Interestingly, the dose of Tim- 4 is very important for the fate of T cells. High doses of Tim-4 promote T cell proliferation, while low doses exert the opposite effect. The explanation for these effects may be that Tim- 4 binds unknown ligands with higher affinity than Tim-1 on $\mathrm{T}$ cells, transmitting negative signals. Alternatively, the interaction of Tim-1-Tim-4 may transmit a negative signal at a lower ligand density, similar to the agonist-antagonist phenomenon observed when peptide ligands are changed, and this inhibition is reversed by higher Tim- 4 concentrations $(41,42)$. Another study showed that Tim4 inhibits the activation of naive rather than activated $\mathrm{T}$ cells. Since Tim-1 is not expressed on naive T cells, the inhibitory effect of Tim-4 may depend on unknown ligands other than Tim-1. Thus, Tim- 4 has at least two types of ligands: one that promotes $\mathrm{T}$ cell activation and another that inhibits $\mathrm{T}$ cell activation. These results suggested that Tim- 4 might regulate $\mathrm{T}$ cell depending on the activation status of $\mathrm{T}$ cells, probably by binding different ligands (14). A recent study reported that Tim-4 inhibits the production of nitric oxide (NO) and cytokines in LPS-treated macrophages by inhibiting the nuclear factor kappa $\mathrm{B}(\mathrm{NF}-\kappa \mathrm{B})$ pathway or janus activating kinase 2 (Jak2)/signal transducer and activator of transcription 1 (STAT1) signaling (43). In summary, Tim- 4 is expressed on different cell types and plays various roles in regulating immunity.

\section{THE LIGANDS OF TIMS}

Published studies have shown that the soluble Tim-4-Ig fusion protein specifically binds to Tim-1-transfected cells, while the soluble Tim-1-Ig fusion protein also specifically binds to Tim-4transfected cells. These studies confirm the interaction between Tim- 4 and Tim-1. In addition, Tim-4-Ig binds to activated T cells that express Tim-1 at high levels, and this binding is blocked by anti-Tim antibodies. Thus, Tim- 4 is indeed the natural ligand of Tim-1 (41). Another study showed that Tim-4 binds to (phosphatidylserine) PS exposed on the surface of apoptotic cells. Hence, PS was identified as another ligand of Tim-4 (44). However, a recent study failed to detect a direct interaction between Tim-1 and Tim-4 (45). Miyanishi et al. showed that Ba/ F3 B cells expressing Tim-1 or Tim- 4 bind to exosomes through PS. PS is present on the surface of exosomes and is involved in signal transduction between cells (44). This finding indicates that the Tim-1-Tim-4 interaction occurs through the PS bridge. Therefore, the interaction between Tim-1 and Tim- 4 is indirect.

Adequate research has confirmed that Galectin-9 (Gal-9) is recognized as a ligand of Tim-3. It binds to the carbohydrate structure of the $\mathrm{IgV}$ domain of Tim-3, which contains two Nglycosylation sites. The interaction between Gal-9 and Tim-3 triggers the death of Th1 cells, thereby inhibiting tissue inflammation and inhibiting the progression of EAE (13). Carcinoembryonic antigen cell adhesion molecule 1 (Ceacam1), with a molecular weight of $60 \mathrm{kDa}$, was recently characterized as another candidate Tim-3 ligand that binds to the Tim-3 IgV domain (46). Ceacam1 is expressed on activated T cells and involved in T cell suppression (47). Tim-3 and Ceacam1 are coexpressed and form a heterodimer. This coexpression is necessary for the inhibitory function of Tim-3. Ceacam 1 forms heterodimer interactions in cis or in trans through its $\mathrm{N}$-terminal domains, and both cis and trans interactions between Ceacam1 and Tim-3 affect the immune tolerance of T cells (46). In addition, high-mobility group box 1 (HMGB1) and PS have also been identified as Tim-3 ligands. HMGB1 is mainly related to inhibition of the innate immune response, while PS is related to the clearance of apoptotic cells $(48,49)$. An understanding of how these ligands coordinate their interactions with Tim-3 and regulate immunity is important.

As discussed above, PS has been identified as a ligand of Tim-4. The crystal structure of Tim- 4 showed that the CC' and FG loops in the IgV domain of Tim-4 create a narrow cavity. A metal ion-dependent ligand binding site (MILIBS) is specifically responsible for the recognition of PS (50). The hydrophilic head of PS penetrates into the MILIBS, its acidic phosphate group is coordinated with metal ions, and the fatty acid tail of PS interacts with the aromatic residues of the FG loop. The hydrophobic residues in the FG loop are essential for PS recognition (51). The single deletion of aromatic residues in 
the FG loop reduces the binding of the Tim protein to PS in liposomes by approximately $70 \%$, while the double mutation completely eliminates PS binding (50).

In addition, PS is a phospholipid present on dying cells and is a typical "eat me" signal. Tim- 4 specifically bind to PS exposed on the surface of apoptotic bodies (AB) via the IgV domain, and then mediate engulfment by macrophages (44). Effective clearance of apoptotic bodies maintains normal tissue homeostasis in organisms. The blockade of Tim- 4 binding to PS leads to deficient clearance of apoptotic cells and results in systemic autoimmunity.

\section{TIM FAMILY IN AUTOIMMUNE DISEASE}

The Tim family plays an important role in regulating immunity. The Tim family has also been reported to exert immunomodulatory effects on many autoimmune diseases. Here, we use multiple sclerosis (MS), rheumatoid arthritis (RA), systemic lupus erythematosus (SLE) and type 1 diabetes (T1D) as examples to summarize the roles of the Tim family in autoimmune diseases (summarized in Table 2).

\section{The Signaling Pathway of Tims}

Tim-1 antibodies were used to identify the signaling pathway by which Tim- 1 activates T cells. Overexpression of Tim-1 leads to nuclear factor of activated T-cells (NFAT)/activatorprotein-1 (AP-1) transcriptional activation, which depends on Y276 in the cytoplasmic tail of Tim-1 (63). In addition, Tim-1 is recruited to the TCR signaling complex in human $\mathrm{T}$ cells through its interaction with CD3. The increase in signaling events related to TCRs include the phosphorylation of Zap70 and IL-2 inducible T cell kinase (ITK). In addition, ITK and phosphoinositide 3kinase $(\mathrm{PI} 3 \mathrm{~K})$ complexes are recruited to the TCR signaling complex (64). After a tyrosine in Tim-1 is phosphorylated in a Lck-dependent manner, the p85 linker subunit of PI3K is directly recruited, leading to PI3K activation (65). Based on these studies, Tim-1-mediated $\mathrm{T}$ cell activation may require PI3K activation.

Tim-3 was identified as specifically expressed on the surface of $\mathrm{CD}^{+}$and $\mathrm{CD}^{+} \mathrm{T}$ cells. Studies have found that the tyrosine residues in the cytoplasmic region of Tim-3 are related to $\mathrm{T}$ cell signaling (31). When Tim-3 does not bind to its ligand, Tyr256/ Tyr263 in the cytoplasmic region of Tim-3 interacts with HLA-B associated transcript 3 (Bat3), and Bat 3 recruits the tyrosine kinases Lck to maintains T cell activation (66). However, when Tim-3 binds to the Gal-9, the phosphorylation of Tyr256 and Tyr263 is triggered by ITK (67), then releases Bat 3 from Tim-3 and inhibits the T cell signaling by tyrosine kinase Fyn recruitment (68).

Tim-4 has been shown to increase the levels of p-extracellular regulated kinase (ERK) $1 / 2$ and p-Akt in $\mathrm{CD}^{+} \mathrm{T}$ cells by crosslinking with Tim-1. Treatment of naive $\mathrm{T}$ cells with inhibitory Tim-4-Ig reduces the phosphorylation of linker for activation of T cells (LAT) and ERK 1/2 (14). In addition, Tim-4 inhibits the mitogen-activated protein kinase (MAPK) pathway in T cells.

In summary, Tim proteins participate in the regulation of many signaling pathways, most of which are related to the pathogenesis of autoimmune diseases. Therefore, an understanding of the role of Tims in different autoimmune diseases and their possible signaling pathways and mechanisms will provide new insights to improve immunotherapy. However, the mechanisms by which Tims regulate autoimmune diseases through these signaling pathways are not yet fully understood, and more research is needed to achieve continuous improvements before clinical treatment.

\section{Tims and MS}

Most evidence for the roles of Tims in autoimmune diseases has been derived from studies of mouse EAE models. The findings from these studies enable us to understand the effect of

TABLE 2 | Studies examining the roles of Tim family members in autoimmune diseases.

\begin{tabular}{|c|c|c|c|}
\hline Tim & $\begin{array}{l}\text { Autoimmune } \\
\text { disease }\end{array}$ & Conclusion & Ref \\
\hline \multirow[t]{4}{*}{ Tim-1 } & MS & Tim-1/- B cell mice developed more severe EAE. Transfer of Tim $-1^{+} B$ cells reduced the severity of EAE in mice. & $(28)$ \\
\hline & RA & $\begin{array}{l}\text { A polymorphism in the Tim-1 gene was related to RA in a Chinese Hui population, and a polymorphism of the Tim-1 } \\
\text { promoter region may be related to the susceptibility to RA in Korean populations. }\end{array}$ & \\
\hline & SLE & $\begin{array}{l}\text { Tim-1 expression in PBMCs was increased in patients with SLE compared with healthy controls and was positively } \\
\text { correlated with IL-10 expression. }\end{array}$ & $(54)$ \\
\hline & T1D & The numbers of Tim-1+ Tregs and Tim-4+ Tregs in patients with T1D and NOD mice were significantly reduced. & $(55)$ \\
\hline \multirow[t]{4}{*}{ Tim-3 } & MS & $\begin{array}{l}\text { Tim-3 expression in PBMCs from patients with MS helped predict the prognosis of the disease. Higher Tim- } 3 \text { expression } \\
\text { was associated with a better prognosis than lower Tim-3 expression. }\end{array}$ & $(56)$ \\
\hline & RA & $\begin{array}{l}\text { Increased expression of Tim-3 in peripheral blood T cells from patients with RA was negatively correlated with the DAS } 28 \\
\text { and plasma TNF- } \alpha \text { levels. }\end{array}$ & $(57)$ \\
\hline & SLE & The expression of Tim-3 and Gal-9 in T cells was increased in patients with SLE compared with healthy controls. & $(58)$ \\
\hline & T1D & $\begin{array}{l}\text { In mice treated with a Gal-9 plasmid, inflammation of the pancreatic islets was reduced, and the number of Th1 cells was } \\
\text { significantly reduced. }\end{array}$ & $(59)$ \\
\hline \multirow[t]{4}{*}{ Tim-4 } & MS & Tim- 4 has been shown to play a critical role in the $T$ cell-mediated immune response. & \\
\hline & $\mathrm{RA}$ & $\begin{array}{l}\text { Increased expression of Tim-3 in peripheral blood T cells from patients with RA was negatively correlated with the DAS28 } \\
\text { and plasma TNF- } \alpha \text { levels. }\end{array}$ & (61) \\
\hline & SLE & $\begin{array}{l}\text { The Tim- } 4 \text { mRNA was expressed at significantly higher levels in PBMCs from patients with SLE than in PBMCs from } \\
\text { healthy controls and was positively correlated with Tim- } 1 \text { mRNA and serum TNF- } \alpha \text { levels. }\end{array}$ & (62) \\
\hline & T1D & The numbers of Tim $-1^{+}$Tregs and Tim-4+ Tregs in patients with T1D and NOD mice were significantly reduced. & (55) \\
\hline
\end{tabular}


autoimmune pathology, especially regarding the $\mathrm{T}$ cell inflammatory response in the central nervous system (CNS) (69). MS is an autoimmune disease characterized by inflammation of the white matter in the CNS. This disease most commonly affects the white matter around the ventricle, optic nerve, spinal cord, brain stem and cerebellum (70). EAE is a mouse model of MS. The pathogenesis of EAE is similar to that of MS, which provides new insights into the pathology of MS.

Xiao showed that a Tim-1 deficiency in B lymphocytes disrupts the balance between regulatory and proinflammatory cytokines in B cells. Mice with Tim- $1^{-/-}$B cells exhibit an enhanced pathogenic Th1/Th17 response, a decreased number of Foxp $3^{+}$Tregs and reduced IL-10 expression in CNS-derived T cells, resulting in a worse EAE clinical score (28). In addition, the adoptive transfer of Tim-1+B cells not only alleviates EAE in wild-type mice but also decreases the severity of EAE in the Tim$1^{-/-} \mathrm{B}$ cell mouse model, showing that Tim-1 is associated with the severity of EAE by regulating the balance between pathogenic $\mathrm{T}$ cells and protective Tregs. Tim -4 has been shown to play a critical role in the T cell-mediated immune response. On the one hand, treatment with a Tim-4 blocking antibody in vivo reduces the $\mathrm{T}$ cell-mediated inflammatory response produced in EAE mice (14). On the other hand, the Tim-4-Fc fusion protein inhibits the activation of naive $\mathrm{T}$ cells in vitro by inhibiting the activation of the MAPK pathway, inhibits the differentiation of Th17 cells and prevents IL-17 production. Notably, the inhibitory effect of the Tim-4-Fc fusion protein is independent of Tim-1 and requires $\operatorname{IgV}$ and mucin domains (60). Based on these studies, Tim- 4 has a bimodal regulatory function that depends on the activation status of T cells: an inhibitory effect of Tim-4 on naive $\mathrm{T}$ cells and a positive regulatory effect on activated $\mathrm{T}$ cells.

Tim-3 is expressed on CD $4^{+}$Th1 cells that secrete IFN- $\gamma(21)$. It also ameliorates the symptoms of EAE by inducing the death of pathogenic Th1 cells, and inhibition of Tim-3 aggravates the symptoms of EAE. The expression of both Gal-9 and Tim-3 on Th1 cells in vitro induces Th1 cell death and ameliorates EAE (13). During the induction of EAE, the administration of Gal-9 in vivo reduces $\mathrm{T}$ cell proliferation and IFN- $\gamma$ production, changes related to reductions in disease morbidity and mortality. In contrast, inhibition of Gal-9 in vivo with an siRNA exacerbates the development of EAE. Dysregulation of Tim-3 expression in MS has been reported in clinical studies. Koguchi et al. studied $\mathrm{CD}^{+} \mathrm{T}$ cell clones isolated from the CSF of patients with MS. Compared with $\mathrm{CD}^{+}{ }^{+} \mathrm{T}$ cells from healthy controls, $\mathrm{CD} 4^{+} \mathrm{T}$ cells from patients with MS express lower levels of Tim-3 and produce more IFN- $\gamma$ (71). Tim-3 signaling also induces the death of specific $\mathrm{CD}^{+} \mathrm{T}$ cells, and the use of Tim-3-blocking antibodies exacerbates $\mathrm{CD}^{+} \mathrm{T}$ cell-mediated EAE (72). Yang et al. examined Tim-3 function on $\mathrm{CD}^{+} \mathrm{T}$ cells isolated from the circulatory system of healthy controls and patients with MS. Blocking Tim-3 during T cell stimulation significantly promotes the secretion of IFN- $\gamma$ in healthy controls. Tim-3 inhibition has no effect on treated patients, suggesting that patients with MS have defects in Tim-3-mediated immunoregulation (73). According to recent studies, the expression levels of Tim-3 on peripheral blood mononuclear cells (PBMCs) from patients with MS help predict the prognosis of the disease. Lower expression levels of Tim-3 on PBMCs are associated with an increased possibility of progression to secondary progressive multiple sclerosis (SPMS), while higher Tim-3 expression levels on PBMCs are associated with a benign prognosis 10 years later (56).

\section{Tims and RA}

$\mathrm{RA}$ is a systemic inflammatory autoimmune disease characterized by joint pain and swelling. In severe cases, it can lead to joint deformities and loss of function (74). RA affects $0.5-$ $1 \%$ of the adult population and is more common in women (75). Although the pathogenesis of RA remains elusive, multiple factors are widely accepted to be involved. Genetic, environmental and hormonal factors may all contribute to the pathogenesis of RA $(76,77)$.

Recently, polymorphisms in Tim genes were reported to be potential risk factors for RA. Xu et al. reported that Tim-1 $(-1637 \mathrm{~A}>\mathrm{G},-232 \mathrm{~A}>\mathrm{G})$, Tim-3 $(-1541 \mathrm{C}>\mathrm{T},+4259 \mathrm{G}>\mathrm{T})$ and Tim-4 (SNP rs7700944) gene polymorphisms are related to RA susceptibility in the Chinese Hui population (52, 78, 79). Similar results were also reported for other national populations $(53,80)$. Tim-4 is involved in the immunoregulation of collagen-induced arthritis (CIA), and it exhibits dual functions, depending on the phase of CIA. During the induction phase, treatment with antiTim-4 monoclonal antibodies exacerbates the development of CIA in mice. In contrast, during the effector phase, treatment with antiTim-4 monoclonal antibodies reduces proinflammatory cytokine levels in the ankle joint, significantly inhibiting the progression of CIA (61).

Tim-3 may be a potential new marker for assessing the severity of RA. The expression levels of Tim-3 on PBMCs from patients with RA have been reported. Liu et al. showed increased expression of Tim- 3 on peripheral blood $\mathrm{CD}^{+}{ }^{+} \mathrm{T}$ cells, $\mathrm{CD}^{+} \mathrm{T}$ cells, NKT cells and monocytes from patients with RA. The percentage of Tim $-3^{+}$cells is negatively correlated with the 28 -joint disease activity score (DAS28) and plasma tumor necrosis factor alpha (TNF- $\alpha$ ) levels (57). In another study, Tim-3 expression on $\mathrm{CD}^{+}$and $\mathrm{CD}^{+} \mathrm{T}$ cells was shown to be negatively correlated with the progression of RA (81). In addition, the number of Tim $-3^{+}$Foxp $3^{+}$Tregs is decreased in patients with RA and is negatively correlated with RA disease activity (82). Based on accumulating evidence, the Tim-3-Gal-9 pathway may play an essential role in the induction and development of RA, and it may be a clinical target for the treatment and alleviation of RA. In an animal model, treatment with Gal-9 was shown to induce naive $\mathrm{T}$ cells to differentiate into Tregs, not only reducing the production of proinflammatory cytokines in mouse joints but also decreasing the number of Tim $-3^{+} \mathrm{CD} 4^{+} \mathrm{T}$ cells in the peripheral blood (83). In a clinical study, significantly higher Gal-9 expression in several $\mathrm{T}$ cell subsets and plasma was observed in patients with RA than in healthy controls. After 12 weeks of treatment with a calcineurin inhibitor, Gal-9 expression levels in individuals with a good therapeutic response were significantly lower than in 
those with a poor therapeutic response (84). Tim-3 is considered a useful biomarker for determining disease activity and progression. However, the current knowledge on Tim-3targeted therapy for RA is still limited, and more studies in humans are required to provide further evidence (85).

\section{Tims and SLE}

SLE is an autoimmune disease with diverse clinical manifestations involving multiple organs. Its etiology is unclear, and it is related to various factors, including genetic, immune, and hormonal factors (86-89).

Lupus nephritis is the main risk factor for the overall morbidity and mortality of SLE and is related to the dysregulation of Th1 and Th2 responses (90). Tim-1 has an important role in regulating the Th1/Th2 response (91). Studies of mouse models of nephritis have suggested that when an inhibitory anti-Tim-1 antibody (RMT1-10) is administered to mice with nephritis, Foxp $3^{+} \mathrm{T}$ cells accumulate in the mice, and the expression of the IL-10 mRNA increases. RMT1-10 treatment reduces the urinary excretion and renal expression of Tim-1, reflecting an alleviation of interstitial injury (92). Previous studies have suggested that patients with SLE show increased expression of Tim-1 in PBMCs compared with healthy people, and Tim-1 expression is positively correlated with IL-10 expression. Moreover, this study also found significantly increased levels of the Tim-1 mRNA in patients with active SLE (SLE disease activity index (SLEDAI) $>6$ ), which indicates that Tim-1 mRNA expression in PBMCs is related to the disease activity of patients with SLE (54). Interestingly, in another study, researchers found that the mRNA expression levels of Tim-4 and Tim-1 were positively correlated in patients with SLE, but this correlation was not obvious in healthy controls. However, the authors failed to detect a significant difference in the Tim-1 mRNA expression levels between patients with SLE and healthy controls. This difference may be due to the distinctive SLEDAI of the subjects participating in each study (62). In summary, unlike other Tim molecules, research on the role of Tim-1 in SLE is still limited, and more research is needed to explore this protein in the future.

Th1 and Th17 immune dysregulation is one of the causes of SLE (93). Tim-3 was initially identified on activated Th1 and Th17 cells and induced $\mathrm{T}$ cell death after binding to its ligand, Gal-9 (94). Jiao et al. investigated the expression of Tim-3 and Gal-9 in patients with SLE and healthy controls. The expression of Tim-3 and Gal-9 on various T cells (including $\mathrm{CD}^{+}{ }^{+} \mathrm{T}$ cells, $\mathrm{CD} 8^{+} \mathrm{T}$ cells, and $\mathrm{CD}_{5} 6^{+} \mathrm{T}$ cells) was significantly higher in patients with SLE than in healthy controls (58). Another study indicated that the plasma level of soluble Tim-3 (sTim-3) was increased in patients with SLE and positively correlated with anti-dsDNA antibodies, SLEDAI score, erythrocyte sedimentation rate (ESR), and urine albumin levels (95). All these studies illustrated that Tim-3 is potentially useful as an effective biomarker for evaluating indicators of SLE disease activity.

Similar to RA, insufficient clearance of $A B$ is also a cause of $\mathrm{SLE}$. If $\mathrm{ABs}$ are not engulfed by macrophages or DCs, the antigens and harmful substances from $\mathrm{ABs}$ will trigger an immune response, thereby promoting the progression of $\operatorname{SLE}(96,97)$. The elimination of $\mathrm{ABs}$ is a key mechanism for maintaining normal tissue homeostasis in multicellular organisms. Tim-4 binds to PS and exposes it on the surface of ABs, presenting a signal to macrophages to trigger engulfment. Tim- 4 mediates the clearance of ABs by macrophages. The mechanism of apoptotic cell phagocytosis is as follows: $\mathrm{Ba} / \mathrm{F} 3$ transformants expressing the Tim- 4 complex and integrin $\alpha(\mathrm{v}) \beta$ (3) bind to and phagocytose apoptotic cells in the presence of milk fat globular epidermal growth factor VIII (MFG-E8) (98). A recent study showed that mice lacking Tim-4 or MFG-E8 rarely develop antibodies (99). In contrast, mice lacking both Tim-4 and MFG-E8 produce high levels of anti-dsDNA antibodies, indicating that Tim-4 and MFGE8 mediates the clearance of apoptotic bodies, and involved in pathogenesis of SLE (15). In a human study, Zhao et al. observed significantly higher Tim-4 mRNA levels in the PBMCs from patients with SLE, especially those in the active phase of the disease, than those in healthy controls. Moreover, the level of the Tim-4 mRNA in PBMCs from patients with SLE positively correlated with the expression of the Tim-1 mRNA and serum TNF- $\alpha$ levels (62). Overexpressed Tim- 4 may bind to Tim- 1 and promote a Th2-mediated immune response, especially in patients with SLE. TNF- $\alpha$ is mainly secreted by activated macrophages and may induce an increase in Tim- 4 expression, thereby promoting the proliferation of Th2 cells by binding to Tim-1. These findings imply that Tim- 4 exerts a regulatory function in the pathogenesis of SLE.

\section{Tims and T1D}

T1D is a chronic autoimmune disease that is mainly caused by the destruction of islet $\beta$ cells mediated by T lymphocytes (100). Due to the continuous destruction of insulin-producing islet $\beta$ cells, insulin deficiency and hyperglycemia occur. Patients with an uncontrolled disease may suffer from ketoacidosis, which can be life-threatening (101). Noninsulin-based treatment strategies, such as delaying $\beta$ cell failure, stem cell treatment, and islet transplantation, would be optimal to ameliorate T1D in patients and prevent its complications (102-104).

Research by Shimokawa confirmed that $\mathrm{CD}^{+}$Tregs are essential for preventing autoimmune diabetes. Notably, compared with healthy individuals, patients with T1D have fewer CD8 ${ }^{+}$Tregs (105). Tim-1 and Tim- 4 are considered essential for the activation and differentiation of $\mathrm{T}$ lymphocytes. Guo et al. evaluated the expression of Tim-1 and Tim- 4 in Tregs and found that the numbers of Tim $-1^{+}$Tregs and Tim $-4^{+}$Tregs were significantly decreased in both patients with T1D and no obesity diabetes (NOD) mice (55).

The Tim-3 pathway represents an important mechanism for downregulating Th1-mediated autoimmune diseases and promoting the development of immune tolerance. A previous study showed that treating recipient mice with a Tim-3-specific monoclonal antibody accelerated the occurrence of autoimmune diabetes in an adoptive transfer NOD model. In addition, similar results were obtained when researchers treated recipient mice with the Tim-3-Ig fusion protein, which disrupts the integrity of the inhibitory interaction between Tim-3 and its ligand on T cells (106). 
Blockade of the Tim-3 pathway accelerates diabetes in NOD mice. This effect may be mediated by inhibiting the immunosuppressive function of Tregs. Furthermore, Gal-9 was identified as a ligand for Tim-3 and shown to suppress the Th1 immune response in the development of T1D (107). Compared with control mice, NOD mice overexpressing the Gal-9 were significantly protected from T1D and showed less inflammation of pancreatic islets (59). Many studies have shown that the Tim-3 pathway is involved in Th1-mediated disease, and blocking the signaling by Tim-3 and its ligand Gal-9 may aggravate autoimmune diseases, including T1D (108).

\section{CONCLUSIONS}

Considerable progress has been achieved in understanding the expression and function of the Tim family in autoimmune diseases. Tim proteins are intimately involved in immunoregulation and participate in many diseases, such as allergies, infections, and cancers, by influencing the immune system. The data on the Tim family also provide us with insights into the design of selective targeted therapeutics. Clearly, the expression of Tim molecules is not limited to $\mathrm{T}$ cells, indicating that they perform different functions in a variety of cells to modulate immune responses.

\section{REFERENCES}

1. Wang L, Wang FS, Gershwin ME. Human Autoimmune Diseases: A Comprehensive Update. J Intern Med (2015) 278(4):369-95. doi: 10.1111/ joim. 12395

2. Hemmer B, Kerschensteiner M, Korn T. Role of the Innate and Adaptive Immune Responses in the Course of Multiple Sclerosis. Lancet Neurol (2015) 14(4):406-19. doi: 10.1016/S1474-4422(14)70305-9

3. Mu Q, Zhang H, Luo XM. SLE: Another Autoimmune Disorder Influenced by Microbes and Diet? Front Immunol (2015) 6:608. doi: 10.3389/ fimmu.2015.00608

4. Maria AT, Maumus M, Le Quellec A, Jorgensen C, Noël D, Guilpain P. Adipose-Derived Mesenchymal Stem Cells in Autoimmune Disorders: State of the Art and Perspectives for Systemic Sclerosis. Clin Rev Allergy Immunol (2017) 52(2):234-59. doi: 10.1007/s12016-016-8552-9

5. DiMeglio LA, Evans-Molina C, Oram RA. Type 1 Diabetes. Lancet (2018) 391(10138):2449-62. doi: 10.1016/S0140-6736(18)31320-5

6. Gilhus NE. Myasthenia Gravis. N Engl J Med (2016) 375(26):2570-81. doi: 10.1056/NEJMra1602678

7. Kuchroo VK, Dardalhon V, Xiao S, Anderson AC. New Roles for TIM Family Members in Immune Regulation. Nat Rev Immunol (2008) 8(8):57780. doi: $10.1038 /$ nri2366

8. Meyers JH, Sabatos CA, Chakravarti S, Kuchroo VK. The TIM Gene Family Regulates Autoimmune and Allergic Diseases. Trends Mol Med (2005) 11 (8):362-9. doi: 10.1016/j.molmed.2005.06.008

9. Sonar SS, Hsu YM, Conrad ML, Majeau GR, Kilic A, Garber E, et al. Antagonism of TIM-1 Blocks the Development of Disease in a Humanized Mouse Model of Allergic Asthma. J Clin Invest (2010) 120(8):2767-81. doi: 10.1172/JCI39543

10. Wang J, Qiao L, Hou Z, Luo G. TIM-1 Promotes Hepatitis C Virus Cell Attachment and Infection. J Virol (2017) 91(2):e01583-16. doi: 10.1128/ JVI.01583-16

11. Degauque N, Mariat C, Kenny J, Zhang D, Gao W, Vu MD, et al. Immunostimulatory Tim-1-Specific Antibody Deprograms Tregs and Prevents Transplant Tolerance in Mice. J Clin Invest (2008) 118(2):73541. doi: $10.1172 /$ JCI32562
Emerging evidence suggests that Tim-1 has a potential role in the maintenance and regulation of Bregs. Tim-3 negatively regulates the response of Th1 cells and inhibits the production of inflammatory factors. Similarly, Tim- 4 seems to play a positive role in clearing apoptotic cells and might participate in systemic autoimmune diseases. Therefore, future research on the Tim family is expected to provide new strategies for autoimmune treatment.

\section{AUTHOR CONTRIBUTIONS}

YL searched the references, wrote the first draft of the paper and revised the text. $\mathrm{HC}, \mathrm{ZC}$, JQ, and $\mathrm{HP}$ critically revised the text and provided substantial scientific contributions. $\mathrm{ZZ}$ proposed the project and revised the manuscript. All authors contributed to the article and approved the submitted version.

\section{FUNDING}

This study was supported by the National Natural Science Foundation of China (grant numbers 8181001262 and 81970746) and the Natural Science Foundation of China (grant number 82000748).

12. Umetsu SE, Lee W-L, McIntire JJ, Downey L, Sanjanwala B, Akbari O, et al. TIM-1 Induces $\mathrm{T}$ Cell Activation and Inhibits the Development of Peripheral Tolerance. Nat Immunol (2005) 6(5):447-54. doi: 10.1038/ni1186

13. Zhu C, Anderson AC, Schubart A, Xiong H, Imitola J, Khoury SJ, et al. The Tim-3 Ligand Galectin-9 Negatively Regulates T Helper Type 1 Immunity. Nat Immunol (2005) 6(12):1245-52. doi: 10.1038/ni1271

14. Mizui M, Shikina T, Arase H, Suzuki K, Yasui T, Rennert PD, et al. Bimodal Regulation of T Cell-Mediated Immune Responses by TIM-4. Int Immunol (2008) 20(5):695-708. doi: 10.1093/intimm/dxn029

15. Fang XY, Xu WD, Pan HF, Leng RX, Ye DQ. Novel Insights Into Tim-4 Function in Autoimmune Diseases. Autoimmunity (2015) 48(4):189-95. doi: 10.3109/08916934.2014.983266

16. Xiao S, Zhu B, Jin H, Zhu C, Umetsu DT, DeKruyff RH, et al. Tim-1 Stimulation of Dendritic Cells Regulates the Balance Between Effector and Regulatory T Cells. Eur J Immunol (2011) 41(6):1539-49. doi: 10.1002/ eji.201040993

17. Yeung MY, Ding Q, Brooks CR, Xiao S, Workman CJ, Vignali DA, et al. TIM-1 Signaling Is Required for Maintenance and Induction of Regulatory B Cells. Am J Transplant (2015) 15(4):942-53. doi: 10.1111/ajt.13087

18. Hein RM, Woods ML. TIM-1 Regulates Macrophage Cytokine Production and B7 Family Member Expression. Immunol Lett (2007) 108(1):103-8. doi: 10.1016/j.imlet.2006.11.004

19. So EC, Khaladj-Ghom A, Ji Y, Amin J, Song Y, Burch E, et al. NK Cell Expression of Tim-3: First Impressions Matter. Immunobiology (2019) 224 (3):362-70. doi: 10.1016/j.imbio.2019.03.001

20. Kuchroo VK, Umetsu DT, DeKruyff RH, Freeman GJ. The TIM Gene Family: Emerging Roles in Immunity and Disease. Nat Rev Immunol (2003) 3(6):454-62. doi: 10.1038/nri1111

21. Monney L, Sabatos CA, Gaglia JL, Ryu A, Waldner H, Chernova T, et al. Th1-Specific Cell Surface Protein Tim-3 Regulates Macrophage Activation and Severity of an Autoimmune Disease. Nature (2002) 415(6871):536-41. doi: 10.1038/415536a

22. Liu W, Xu L, Liang X, Liu X, Zhao Y, Ma C, et al. Tim-4 in Health and Disease: Friend or Foe? Front Immunol (2020) 11:537. doi: 10.3389/ fimmu.2020.00537 
23. Ichimura T, Asseldonk EJPV, Humphreys BD, Gunaratnam L, Duffield JS, Bonventre JV. Kidney Injury Molecule-1 Is a Phosphatidylserine Receptor That Confers a Phagocytic Phenotype on Epithelial Cells. J Clin Invest (2008) 118(5):1657-68. doi: 10.1172/JCI34487

24. Nauta FL, Boertien WE, Bakker SJL, van Goor H, van Oeveren W, de Jong PE, et al. Glomerular and Tubular Damage Markers Are Elevated in Patients With Diabetes. Diabetes Care (2011) 34(4):975-81. doi: 10.2337/dc10-1545

25. Feigelstock D, Thompson P, Mattoo P, Zhang Y, Kaplan GG. The Human Homolog of HAVcr-1 Codes for a Hepatitis A Virus Cellular Receptor. J Virol (1998) 72(8):6621-8. doi: 10.1128/JVI.72.8.6621-6628.1998

26. Xiao S, Najafian N, Reddy J, Albin M, Zhu C, Jensen E, et al. Differential Engagement of Tim-1 During Activation can Positively or Negatively Costimulate T Cell Expansion and Effector Function. J Exp Med (2007) 204(7):1691-702. doi: 10.1084/jem.20062498

27. Xiao S, Brooks CR, Zhu C, Wu C, Sweere JM, Petecka S, et al. Defect in Regulatory B-Cell Function and Development of Systemic Autoimmunity in T-Cell Ig Mucin 1 (Tim-1) Mucin Domain-Mutant Mice. Proc Natl Acad Sci USA (2012) 109(30):12105-10. doi: 10.1073/pnas.1120914109

28. Xiao S, Brooks CR, Sobel RA, Kuchroo VK. Tim-1 Is Essential for Induction and Maintenance of IL-10 in Regulatory B Cells and Their Regulation of Tissue Inflammation. J Immunol (2015) 194(4):1602-8. doi: 10.4049/ jimmunol.1402632

29. Nakae S, Iikura M, Suto H, Akiba H, Umetsu DT, Dekruyff RH, et al. TIM-1 and TIM-3 Enhancement of Th2 Cytokine Production by Mast Cells. Blood (2007) 110(7):2565-8. doi: 10.1182/blood-2006-11-058800

30. Anderson AC, Lord GM, Dardalhon V, Lee DH, Sabatos-Peyton CA, Glimcher LH, et al. T-Bet, A Th1 Transcription Factor Regulates the Expression of Tim-3. Eur J Immunol (2010) 40(3):859-66. doi: 10.1002/eji.200939842

31. Das M, Zhu C, Kuchroo VK. Tim-3 and Its Role in Regulating Anti-Tumor Immunity. Immunol Rev (2017) 276(1):97-111. doi: 10.1111/imr.12520

32. Anderson AC, Anderson DE, Bregoli L, Hastings WD, Kassam N, Lei C, et al. Promotion of Tissue Inflammation by the Immune Receptor Tim-3 Expressed on Innate Immune Cells. Science (New York NY) (2007) 318 (5853):1141-3. doi: 10.1126/science.1148536

33. Ocaña-Guzman R, Torre-Bouscoulet L, Sada-Ovalle I. TIM-3 Regulates Distinct Functions in Macrophages. Front Immunol (2016) 7:229. doi: 10.3389/fimmu.2016.00229

34. Tan S, Xu Y, Wang Z, Wang T, Du X, Song X, et al. Tim-3 Hampers Tumor Surveillance of Liver-Resident and Conventional NK Cells by Disrupting PI3K Signaling. Cancer Res (2020) 80(5):1130-42. doi: 10.1158/00085472.Can-19-2332

35. Hastings WD, Anderson DE, Kassam N, Koguchi K, Greenfield EA, Kent SC, et al. TIM-3 Is Expressed on Activated Human CD4+ T Cells and Regulates Th1 and Th17 Cytokines. Eur J Immunol (2009) 39(9):2492-501. doi: 10.1002/eji.200939274

36. Nakae S, Iwakura Y, Suto H, Galli SJ. Phenotypic Differences Between Th1 and Th17 Cells and Negative Regulation of Th1 Cell Differentiation by IL17. J leukocyte Biol (2007) 81(5):1258-68. doi: 10.1189/jlb.1006610

37. Liu Z, McMichael EL, Shayan G, Li J, Chen K, Srivastava R, et al. Novel Effector Phenotype of Tim-3(+) Regulatory T Cells Leads to Enhanced Suppressive Function in Head and Neck Cancer Patients. Clin Cancer Res (2018) 24(18):4529-38. doi: 10.1158/1078-0432.CCR-17-1350

38. Frisancho-Kiss S, Nyland JF, Davis SE, Barrett MA, Gatewood SJ, Njoku DB, et al. Cutting Edge: T Cell Ig Mucin-3 Reduces Inflammatory Heart Disease by Increasing CTLA-4 During Innate Immunity. I Immunol (2006) 176 (11):6411-5. doi: 10.4049/jimmunol.176.11.6411

39. Yang PC, Xing Z, Berin CM, Soderholm JD, Feng BS, Wu L, et al. TIM-4 Expressed by Mucosal Dendritic Cells Plays a Critical Role in Food AntigenSpecific Th2 Differentiation and Intestinal Allergy. Gastroenterology (2007) 133(5):1522-33. doi: 10.1053/j.gastro.2007.08.006

40. Feng BS, Chen X, He SH, Zheng PY, Foster J, Xing Z, et al. Disruption of T-Cell Immunoglobulin and Mucin Domain Molecule (TIM)-1/TIM4 Interaction as a Therapeutic Strategy in a Dendritic Cell-Induced Peanut Allergy Model. J Allergy Clin Immunol (2008) 122(1):55-61, 61.e1-7. doi: 10.1016/ j.jaci.2008.04.036

41. Meyers JH, Chakravarti S, Schlesinger D, Illes Z, Waldner H, Umetsu SE, et al. TIM-4 Is the Ligand for TIM-1, and the TIM-1-TIM-4 Interaction
Regulates T Cell Proliferation. Nat Immunol (2005) 6(5):455-64. doi: $10.1038 /$ ni1 185

42. Racioppi L, Ronchese F, Matis LA, Germain RN. Peptide-Major Histocompatibility Complex Class II Complexes With Mixed Agonist/ Antagonist Properties Provide Evidence for Ligand-Related Differences in T Cell Receptor-Dependent Intracellular Signaling. J Exp Med (1993) 177 (4):1047-60. doi: 10.1084/jem.177.4.1047

43. Xu LY, Qi JN, Liu X, Ma HX, Yuan W, Zhao PQ, et al. Tim-4 Inhibits NO Generation by Murine Macrophages. PLoS One (2015) 10(4):e0124771. doi: 10.1371/journal.pone.0124771

44. Miyanishi M, Tada K, Koike M, Uchiyama Y, Kitamura T, Nagata S. Identification of Tim4 as a Phosphatidylserine Receptor. Nature (2007) 450(7168):435-9. doi: 10.1038/nature06307

45. Sizing ID, Bailly V, McCoon P, Chang W, Rao S, Pablo L, et al. EpitopeDependent Effect of Anti-Murine TIM-1 Monoclonal Antibodies on T Cell Activity and Lung Immune Responses. J Immunol (2007) 178(4):2249-61. doi: 10.4049/jimmunol.178.4.2249

46. Huang YH, Zhu C, Kondo Y, Anderson AC, Gandhi A, Russell A, et al. CEACAM1 Regulates TIM-3-Mediated Tolerance and Exhaustion. Nature (2015) 517(7534):386-90. doi: 10.1038/nature13848

47. Chen L, Chen Z, Baker K, Halvorsen EM, da Cunha AP, Flak MB, et al. The Short Isoform of the CEACAM1 Receptor in Intestinal T Cells Regulates Mucosal Immunity and Homeostasis via Tfh Cell Induction. Immunity (2012) 37(5):930-46. doi: 10.1016/j.immuni.2012.07.016

48. DeKruyff RH, Bu X, Ballesteros A, Santiago C, Chim YL, Lee HH, et al. T Cell/Transmembrane, Ig, and Mucin-3 Allelic Variants Differentially Recognize Phosphatidylserine and Mediate Phagocytosis of Apoptotic Cells. J Immunol (2010) 184(4):1918-30. doi: 10.4049/jimmunol.0903059

49. Tang D, Lotze MT. Tumor Immunity Times Out: TIM-3 and HMGB1. Nat Immunol (2012) 13(9):808-10. doi: 10.1038/ni.2396

50. Santiago C, Ballesteros A, Martínez-Muñoz L, Mellado M, Kaplan GG, Freeman GJ, et al. Structures of T Cell Immunoglobulin Mucin Protein 4 Show a Metal-Ion-Dependent Ligand Binding Site Where Phosphatidylserine Binds. Immunity (2007) 27(6):941-51. doi: 10.1016/ j.immuni.2007.11.008

51. Kobayashi N, Karisola P, Peña-Cruz V, Dorfman DM, Jinushi M, Umetsu SE, et al. TIM-1 and TIM-4 Glycoproteins Bind Phosphatidylserine and Mediate Uptake of Apoptotic Cells. Immunity (2007) 27(6):927-40. doi: 10.1016/j.immuni.2007.11.011

52. Xu JR, Yang Y, Liu XM, Sun JY, Wang YJ. Polymorphisms of the TIM-1 Gene Are Associated With Rheumatoid Arthritis in the Chinese Hui Minority Ethnic Population. Genet Mol Res GMR (2012) 11(1):61-9. doi: 10.4238/2012.January.9.7

53. Chae SC, Park YR, Song JH, Shim SC, Yoon KS, Chung HT. The Polymorphisms of Tim-1 Promoter Region Are Associated With Rheumatoid Arthritis in a Korean Population. Immunogenetics (2005) 56 (10):696-701. doi: 10.1007/s00251-004-0743-5

54. Wang Y, Meng J, Wang X, Liu S, Shu Q, Gao L, et al. Expression of Human TIM-1 and TIM-3 on Lymphocytes From Systemic Lupus Erythematosus Patients. Scand J Immunol (2008) 67(1):63-70. doi: 10.1111/j.13653083.2007.02038.x

55. Guo H, Shen Y, Kong YH, Li S, Jiang R, Liu C, et al. The Expression of Tim-1 and Tim-4 Molecules in Regulatory T Cells in Type 1 Diabetes. Endocrine (2020) 68(1):64-70. doi: 10.1007/s12020-019-02173-8

56. Lavon I, Heli C, Brill L, Charbit H, Vaknin-Dembinsky A. Blood Levels of Co-Inhibitory-Receptors: A Biomarker of Disease Prognosis in Multiple Sclerosis. Front Immunol (2019) 10:835. doi: 10.3389/fimmu.2019.00835

57. Liu Y, Shu Q, Gao L, Hou N, Zhao D, Liu X, et al. Increased Tim-3 Expression on Peripheral Lymphocytes From Patients With Rheumatoid Arthritis Negatively Correlates With Disease Activity. Clin Immunol (2010) 137(2):288-95. doi: 10.1016/j.clim.2010.07.012

58. Jiao Q, Qian Q, Zhao Z, Fang F, Hu X, An J, et al. Expression of Human T Cell Immunoglobulin Domain and Mucin-3 (TIM-3) and TIM-3 Ligands in Peripheral Blood From Patients With Systemic Lupus Erythematosus. Arch Dermatol Res (2016) 308(8):553-61. doi: 10.1007/s00403-016-1665-4

59. Chou FC, Kuo CC, Wang YL, Lin MH, Linju Yen B, Chang DM, et al. Overexpression of Galectin-9 in Islets Prolongs Grafts Survival via 
Downregulation of Th1 Responses. Cell Transplant (2013) 22(11):2135-45. doi: $10.3727 / 096368912 X 657891$

60. Cao W, Ryan M, Buckley D, O'Connor R, Clarkson MR. Tim-4 Inhibition of T-Cell Activation and T Helper Type 17 Differentiation Requires Both the Immunoglobulin V and Mucin Domains and Occurs via the MitogenActivated Protein Kinase Pathway. Immunology (2011) 133(2):179-89. doi: 10.1111/j.1365-2567.2011.03424.x

61. Abe Y, Kamachi F, Kawamoto T, Makino F, Ito J, Kojima Y, et al. TIM-4 has Dual Function in the Induction and Effector Phases of Murine Arthritis. J Immunol (2013) 191(9):4562-72. doi: 10.4049/jimmunol.1203035

62. Zhao P, Xu L, Wang P, Liang X, Qi J, Liu P, et al. Increased Expression of Human T-Cell Immunoglobulin- and Mucin-Domain-Containing Molecule-4 in Peripheral Blood Mononuclear Cells From Patients With System Lupus Erythematosus. Cell Mol Immunol (2010) 7(2):152-6. doi: $10.1038 / \mathrm{cmi} .2009 .118$

63. de Souza AJ, Oriss TB, O'Malley KJ, Ray A, Kane LP. T Cell Ig and Mucin 1 (TIM-1) Is Expressed on In Vivo-Activated T Cells and Provides a Costimulatory Signal for T Cell Activation. Proc Natl Acad Sci USA (2005) 102(47):17113-8. doi: 10.1073/pnas.0508643102

64. Binné LL, Scott ML, Rennert PD. Human TIM-1 Associates With the TCR Complex and Up-Regulates T Cell Activation Signals. J Immunol (2007) 178 (7):4342-50. doi: 10.4049/jimmunol.178.7.4342

65. de Souza AJ, Oak JS, Jordanhazy R, DeKruyff RH, Fruman DA, Kane LP. T Cell Ig and Mucin Domain-1-Mediated T Cell Activation Requires Recruitment and Activation of Phosphoinositide 3-Kinase. J Immunol (2008) 180(10):6518-26. doi: 10.4049/jimmunol.180.10.6518

66. Rangachari M, Zhu C, Sakuishi K, Xiao S, Karman J, Chen A, et al. Bat3 Promotes T Cell Responses and Autoimmunity by Repressing Tim-3Mediated Cell Death and Exhaustion. Nat Med (2012) 18(9):1394-400. doi: $10.1038 / \mathrm{nm} .2871$

67. van de Weyer PS, Muehlfeit M, Klose C, Bonventre JV, Walz G, Kuehn EW. A Highly Conserved Tyrosine of Tim-3 Is Phosphorylated Upon Stimulation by Its Ligand Galectin-9. Biochem Biophys Res Commun (2006) 351(2):5716. doi: $10.1016 / j . b b r c .2006 .10 .079$

68. Lee J, Su EW, Zhu C, Hainline S, Phuah J, Moroco JA, et al. Phosphotyrosine-Dependent Coupling of Tim-3 to T-Cell Receptor Signaling Pathways. Mol Cell Biol (2011) 31(19):3963-74. doi: 10.1128/ MCB.05297-11

69. Rangachari M, Kuchroo VK. Using EAE to Better Understand Principles of Immune Function and Autoimmune Pathology. J Autoimmun (2013) 45:319. doi: 10.1016/j.jaut.2013.06.008

70. Frohman EM, Racke MK, Raine CS. Multiple Sclerosis-the Plaque and Its Pathogenesis. N Engl J Med (2006) 354(9):942-55. doi: 10.1056/ NEJMra052130

71. Koguchi K, Anderson DE, Yang L, O'Connor KC, Kuchroo VK, Hafler DA. Dysregulated T Cell Expression of TIM3 in Multiple Sclerosis. J Exp Med (2006) 203(6):1413-8. doi: 10.1084/jem.20060210

72. Lee SY, Goverman JM. The Influence of T Cell Ig Mucin-3 Signaling on Central Nervous System Autoimmune Disease Is Determined by the Effector Function of the Pathogenic T Cells. J Immunol (2013) 190(10):4991-9. doi: 10.4049/jimmunol.1300083

73. Yang L, Anderson DE, Kuchroo J, Hafler DA. Lack of TIM-3 Immunoregulation in Multiple Sclerosis. J Immunol (2008) 180(7):440914. doi: 10.4049/jimmunol.180.7.4409

74. Sparks JA. Rheumatoid Arthritis. Ann Internal Med (2019) 170(1):Itc1itc16. doi: 10.7326/AITC201901010

75. Batko B, Stajszczyk M, Świerkot J, Urbański K, Raciborski F, Jędrzejewski M, et al. Prevalence and Clinical Characteristics of Rheumatoid Arthritis in Poland: A Nationwide Study. Arch Med Sci AMS (2019) 15(1):134-40. doi: 10.5114 /aoms.2017.71371

76. Viatte S, Barton A. Genetics of Rheumatoid Arthritis Susceptibility, Severity, and Treatment Response. Semin Immunopathology (2017) 39(4):395-408. doi: 10.1007/s00281-017-0630-4

77. Alpízar-Rodríguez D, Finckh A. Environmental Factors and Hormones in the Development of Rheumatoid Arthritis. Semin Immunopathology (2017) 39(4):461-8. doi: 10.1007/s00281-017-0624-2

78. Xu J, Yang Y, Liu X, Wang Y. The $-1541 \mathrm{C}>\mathrm{T}$ and $+4259 \mathrm{G}>\mathrm{T}$ of TIM-3 Polymorphisms Are Associated With Rheumatoid Arthritis Susceptibility in a Chinese Hui Population. Int J immunogenetics (2011) 38(6):513-8. doi: 10.1111/j.1744-313X.2011.01046.x

79. Xu J, Yang Y, Liu X, Wang Y. Genetic Variation and Significant Association of Polymorphism Rs7700944 G>A of TIM-4 Gene With Rheumatoid Arthritis Susceptibility in Chinese Han and Hui Populations. Int $J$ Immunogenetics (2012) 39(5):409-13. doi: 10.1111/j.1744-313X. 2012.01103.x

80. Mosaad YM, El-Bassiony SR, El-Ghaweet AE, Elhindawy MM, El-Deek BS, Sultan WA. TIM-1 Rs41297579 G>A (-1454) and TIM-4 Rs7700944 Gene Polymorphisms as Possible Risk Factor for Rheumatoid Arthritis: Relation to Activity and Severity. Int J immunogenetics (2015) 42(4):254-64. doi: $10.1111 /$ iji.12201

81. Li S, Peng D, He Y, Zhang H, Sun H, Shan S, et al. Expression of TIM-3 on CD4+ and CD8+ T Cells in the Peripheral Blood and Synovial Fluid of Rheumatoid Arthritis. APMIS Acta Pathologica Microbiologica Immunologica Scandinavica (2014) 122(10):899-904. doi: 10.1111/ apm. 12228

82. Sun H, Gao W, Pan W, Zhang Q, Wang G, Feng D, et al. Tim3(+) Foxp3 (+) Treg Cells Are Potent Inhibitors of Effector T Cells and Are Suppressed in Rheumatoid Arthritis. Inflammation (2017) 40(4):1342-50. doi: 10.1007/ s10753-017-0577-6

83. Seki M, Oomizu S, Sakata KM, Sakata A, Arikawa T, Watanabe K, et al. Galectin-9 Suppresses the Generation of Th17, Promotes the Induction of Regulatory T Cells, and Regulates Experimental Autoimmune Arthritis. Clin Immunol (2008) 127(1):78-88. doi: 10.1016/j.clim.2008.01.006

84. Sun J, Sui Y, Wang Y, Song L, Li D, Li G, et al. Galectin-9 Expression Correlates With Therapeutic Effect in Rheumatoid Arthritis. Sci Rep (2021) 11(1):5562. doi: 10.1038/s41598-021-85152-2

85. Li X, Zhao YQ, Li CW, Yuan FL. T Cell Immunoglobulin-3 as a New Therapeutic Target for Rheumatoid Arthritis. Expert Opin Ther Targets (2012) 16(12):1145-9. doi: 10.1517/14728222.2012.726616

86. Tsokos GC, Lo MS, Costa Reis P, Sullivan KE. New Insights Into the Immunopathogenesis of Systemic Lupus Erythematosus. Nat Rev Rheumatol (2016) 12(12):716-30. doi: 10.1038/nrrheum.2016.186

87. Ghodke-Puranik Y, Niewold TB. Immunogenetics of Systemic Lupus Erythematosus: A Comprehensive Review. J Autoimmun (2015) 64:12536. doi: $10.1016 /$ j.jaut.2015.08.004

88. Surace AEA, Hedrich CM. The Role of Epigenetics in Autoimmune/ Inflammatory Disease. Front Immunol (2019) 10:1525. doi: 10.3389/ fimmu.2019.01525

89. Barbhaiya M, Costenbader KH. Environmental Exposures and the Development of Systemic Lupus Erythematosus. Curr Opin Rheumatol (2016) 28(5):497-505. doi: 10.1097/BOR.0000000000000318

90. Almaani S, Meara A, Rovin BH. Update on Lupus Nephritis. Clin J Am Soc Nephrol CJASN (2017) 12(5):825-35. doi: 10.2215/CJN.05780616

91. Du P, Xiong R, Li X, Jiang J. Immune Regulation and Antitumor Effect of TIM-1. J Immunol Res (2016) 2016:8605134. doi: 10.1155/2016/8605134

92. Nozaki Y, Nikolic-Paterson DJ, Snelgrove SL, Akiba H, Yagita H, Holdsworth SR, et al. Endogenous Tim-1 (Kim-1) Promotes T-Cell Responses and Cell-Mediated Injury in Experimental Crescentic Glomerulonephritis. Kidney Int (2012) 81(9):844-55. doi: 10.1038/ ki.2011.424

93. Moulton VR, Suarez-Fueyo A, Meidan E, Li H, Mizui M, Tsokos GC. Pathogenesis of Human Systemic Lupus Erythematosus: A Cellular Perspective. Trends Mol Med (2017) 23(7):615-35. doi: 10.1016/ j.molmed.2017.05.006

94. Han G, Chen G, Shen B, Li Y. Tim-3: An Activation Marker and Activation Limiter of Innate Immune Cells. Front Immunol (2013) 4:449. doi: 10.3389/ fimmu.2013.00449

95. Zhao D, Li C, Yang X, Yan W, Zhang Y. Elevated Soluble Tim-3 Correlates With Disease Activity of Systemic Lupus Erythematosus. Autoimmunity (2021) 54(2):97-103. doi: 10.1080/08916934.2021.1891535

96. Krahling S, Callahan MK, Williamson P, Schlegel RA. Exposure of Phosphatidylserine Is a General Feature in the Phagocytosis of Apoptotic Lymphocytes by Macrophages. Cell Death Differ (1999) 6(2):183-9. doi: 10.1038/sj.cdd. 4400473

97. Fransen JH, Berden JH, Koeter CM, Adema GJ, van der Vlag J, Hilbrands LB. Effect of Administration of Apoptotic Blebs on Disease Development in 
Lupus Mice. Autoimmunity (2012) 45(4):290-7. doi: 10.3109/08916934. 2012.664668

98. Toda S, Hanayama R, Nagata S. Two-Step Engulfment of Apoptotic Cells. Mol Cell Biol (2012) 32(1):118-25. doi: 10.1128/MCB.05993-11

99. Miyanishi M, Segawa K, Nagata S. Synergistic Effect of Tim4 and MFG-E8 Null Mutations on the Development of Autoimmunity. Int Immunol (2012) 24(9):551-9. doi: 10.1093/intimm/dxs064

100. Bluestone JA, Herold K, Eisenbarth G. Genetics, Pathogenesis and Clinical Interventions in Type 1 Diabetes. Nature (2010) 464(7293):1293-300. doi: 10.1038 /nature08933

101. Fazeli Farsani S, Brodovicz K, Soleymanlou N, Marquard J, Wissinger E, Maiese BA. Incidence and Prevalence of Diabetic Ketoacidosis (DKA) Among Adults With Type 1 Diabetes Mellitus (T1D): A Systematic Literature Review. BMJ Open (2017) 7(7):e016587. doi: 10.1136/bmjopen2017-016587

102. Marek-Trzonkowska N, Mysliwiec M, Dobyszuk A, Grabowska M, Techmanska I, Juscinska J, et al. Administration of CD4+CD25highCD127Regulatory T Cells Preserves $\beta$-Cell Function in Type 1 Diabetes in Children. Diabetes Care (2012) 35(9):1817-20. doi: 10.2337/dc12-0038

103. Millman JR, Xie C, Van Dervort A, Gürtler M, Pagliuca FW, Melton DA. Generation of Stem Cell-Derived $\beta$-Cells From Patients With Type 1 Diabetes. Nat Commun (2016) 7:11463. doi: 10.1038/ncomms11463

104. van Belle TL, Coppieters KT, von Herrath MG. Type 1 Diabetes: Etiology, Immunology, and Therapeutic Strategies. Physiol Rev (2011) 91(1):79-118. doi: 10.1152 /physrev.00003.2010

105. Shimokawa C, Kato T, Takeuchi T, Ohshima N, Furuki T, Ohtsu Y, et al. CD8(+) Regulatory T Cells Are Critical in Prevention of AutoimmuneMediated Diabetes. Nat Commun (2020) 11(1):1922. doi: 10.1038/s41467020-15857-x
106. Sánchez-Fueyo A, Tian J, Picarella D, Domenig C, Zheng XX, Sabatos CA, et al. Tim-3 Inhibits T Helper Type 1-Mediated Auto- and Alloimmune Responses and Promotes Immunological Tolerance. Nat Immunol (2003) 4 (11):1093-101. doi: 10.1038/ni987

107. Chou FC, Shieh SJ, Sytwu HK. Attenuation of Th1 Response Through Galectin-9 and T-Cell Ig Mucin 3 Interaction Inhibits Autoimmune Diabetes in NOD Mice. Eur J Immunol (2009) 39(9):2403-11. doi: 10.1002/ eji.200839177

108. Zhao L, Cheng S, Fan L, Zhang B, Xu S. TIM-3: An Update on Immunotherapy. Int Immunopharmacol (2021) 99:107933. doi: 10.1016/ j.intimp.2021.107933

Conflict of Interest: The authors declare that the research was conducted in the absence of any commercial or financial relationships that could be construed as a potential conflict of interest.

Publisher's Note: All claims expressed in this article are solely those of the authors and do not necessarily represent those of their affiliated organizations, or those of the publisher, the editors and the reviewers. Any product that may be evaluated in this article, or claim that may be made by its manufacturer, is not guaranteed or endorsed by the publisher.

Copyright $\odot 2021$ Liu, Chen, Chen, Qiu, Pang and Zhou. This is an open-access article distributed under the terms of the Creative Commons Attribution License (CC BY). The use, distribution or reproduction in other forums is permitted, provided the original author(s) and the copyright owner(s) are credited and that the original publication in this journal is cited, in accordance with accepted academic practice. No use, distribution or reproduction is permitted which does not comply with these terms. 